\title{
Yönetim Kurulu ve Sahiplik Yapısının Finansal Performans Üzerindeki Etkisi: BIST İmalat Sanayi Sektöründe Bir Alan Araştırması *
}

\author{
Impact of the Board of Directors and Ownership Structure on Financial \\ Performance: A Field Study in BIST Manufacturing Industry \\ Dr. Meltem KILIÇ ${ }^{1}$, Doç. Dr. Yücel AYRIÇAY²
}

\begin{abstract}
Özet
Yönetim kurulu ve sahiplik yapısının finansal performans üzerindeki etkisi, finans literatüründe önemli bir araştırma konusu olmuş ve dikkatle incelenmiştir. Bu çalışmada, BIST İmalat Sanayi Sektöründe yer alan firmaların yönetim kurulu ve sahiplik yapılarının finansal performans üzerindeki etkisini ölçmek amaçlanmıştır. Analizlerde, BIST İmalat Sanayi Sektörü'nde faaliyet gösteren 78 aile firmasının 2003-2014 yılları arasındaki yıllık verilerinden yararlanılmıştır. Çalışmada panel veri analizi kullanılmıştır. Regresyon modellerinde bağımlı değişken olarak firmaların aktif karlılığı, özsermaye karlılığı, satışların karlılı̆̆ı, Tobin-Q ve piyasa değeri logaritması; bağımsız değişken olarak en büyük pay sahibinin pay oranı, halka açıklık oranı, yönetim kurulu büyüklüğü ve CEO ikiliği kullanılmıştır. Ayrıca, çalışmada modelin anlamlılığını ve güvenirliliğini artırmak için kaldıraç oranı ve satışların logaritması kontrol değiş̧kenlerine yer verilmiştir. Analiz sonuçlarında genel olarak, yönetim kurulu ve sahiplik yapısı ile finansal performans arasında ilişki olduğu tespit edilmiştir.
\end{abstract}

Anahtar Kelime: Yönetim kurulu yapısı, sahiplik yapısı, finansal performans, panel veri analizi

\begin{abstract}
The relationship between the board of directors and ownership structure on the financial performance has been an important research topic in finance literatüre and has been carefully examined. In this perspective, it is aimed to measure the impact of the board of directors and ownership structure of firms in the BIST Manufacturing Sector on financial performance. In the analysis, 78 family companies operating in the BIST Manufacturing Sector benefited from the annual data for 2003-2014. Panel data analysis is used in the study. In the regression models, return on assets, return on equity, return of sales, Tobin-Q and market value logarithm are used as dependent variables; the share of the largest shareholder, the free float ratio, the size of the board of directors and the CEO duality are used as independent variables. In addition, the leverage ratio and the logarithm of the sales control variables are used to increase the significance and reliability of the model in the study. In the analysis results, it has been determined that there is generally a relationship between the board of directors, ownership structure and financial performance.
\end{abstract}

Key Word: Board of directors structure, ownership structure, financial performance, panel data analysis

\footnotetext{
" Bu çalışma, "Kurumsal Yönetim, Sahiplik Yapısı ve Finansal Performans İlişkisi: BIST’de Bir Alan Araştırması" konulu Doktora tezinden üretilmiştir.

${ }^{1}$ Kahramanmaraş Sütçü İmam Üniversitesi, İ̈BF, meltem.kilic@ hotmail.com, Orcid ID: orcid.org/0000-0001-8978-9076

${ }^{2}$ Kahramanmaraş Sütçü İmam Üniversitesi, İ̈BF, yucelayricay@hotmail.com, Orcid ID: orcid.org/000-0001-5148-39
} 


\section{Giriş}

Bir firmanın temel amacı olan firma değerinin maksimizasyonunun gerçekleştirilebilmesi için önemli unsurlardan biri de finansal performansının yüksek olmasıdır. Finansal performansın yükseltilmesinde etkili olan süreçlerden birisi kurumsal yönetim sürecidir. Kurumsal yönetim süreciyle birlikte firmalar OECD tarafindan yayınlanan kurumsal yönetim ilkelerine uyarak, kurumsal yönetim mekanizmaları ve teorileri üzerinden finansal performanslarını artırabilmektedirler. Özellikle kurumsal yönetim mekanizmaları finansal performansın önemli bir belirleyicisi olarak ifade edilmekte, bu mekanizmalardan yönetim kurulu ve sahiplik yapısının kurumsal yönetim uygulamalarını ve finansal performansı artıracağı konusunda tartışmalar bulunmaktadır (Ho ve Williams, 2003:466). Firmaların kurumsal yönetime geçiş sürecindeki rolü büyük olan yönetim kurulu, pay sahiplerini temsil eden kişiler olarak tanımlanmaktadır. Özellikle pay sahiplerinin çok fazla olduğu firmalarda, pay sahiplerinin vekalet verdikleri kişiler yönetim kurulunda yer almaktadır (Ülgen ve Mirze, 2013:468). Pay sahipleri tarafindan oluşturulan yönetim kurulunun yapısının doğru belirlenmesi gerekmektedir. Çünkü, kurumsal yönetim için yönetim kurulu yapısı ile birlikte, kuruldaki üye sayısı, yönetim kurulu başkanının CEO olup olmadığ1 ve üyelerinin bağımsız olup olmadığı belirlenmektedir (Kula, 2006:35). Yönetim kurulu, hem yapısı hem de belirlediği stratejiler ile firmaların finansal performansı üzerinde etkili oldukları görülmektedir (Okan, vd. 2014:40).

Yönetim kurulu yapısı ile birlikte kurumsal yönetim anlayışının belirleyen önemli ölçütlerden biri de sahiplik yapısıdır. Sahiplik yapısı, firmanın pay sahipleri ve yöneticileri arasındaki menfaat çatışmalarını çözmek için kullanılan içsel kurumsal yönetim mekanizmasıdır (Hu ve Izumida, 2008:72). Firmanın sahiplik yapısı, o firmanın kurumsal yönetim uygulamalarını biçimlendirmekte ve karar alma sürecinde kurumsal yönetim uygulamalarının önem derecesini belirlemektedir. Kurumsal yönetim ve sahiplik yapısı arasındaki ilişki ise firmanın kurumsal yönetim uygulamalarında pay sahiplerinin kontrolünün önemi ve sahiplik yapısının merkezi rolünü belirtmektedir (Gürbüz ve Yakup, 2004:15). Bir firmanın sahiplik yapısının şekillenmesinde o firmanın çevresinden ve kendi iç işleyişinden kaynaklanan faktörlerin etkili olduğu görülmektedir (Yılgör ve Yücel, 2012:43). $\mathrm{Bu}$ nedenle sahiplik yapısı; aile sahipliği, yabancı sahipliği, devlet sahipliği gibi farklı sahiplik yapıları ile anılmaktadır. Firmaların temelindeki bu farklı sahiplik yapıları, farklı finansal performansların ortaya çıkmasına neden olmaktadır. Genel anlamda, kurumsal yönetim mekanizmalarından yönetim kurulu ve sahiplik yapısının firma performansını etkilediği ifade edilebilir. Bu sonuç aşağıdaki şekilde özetlenebilir:

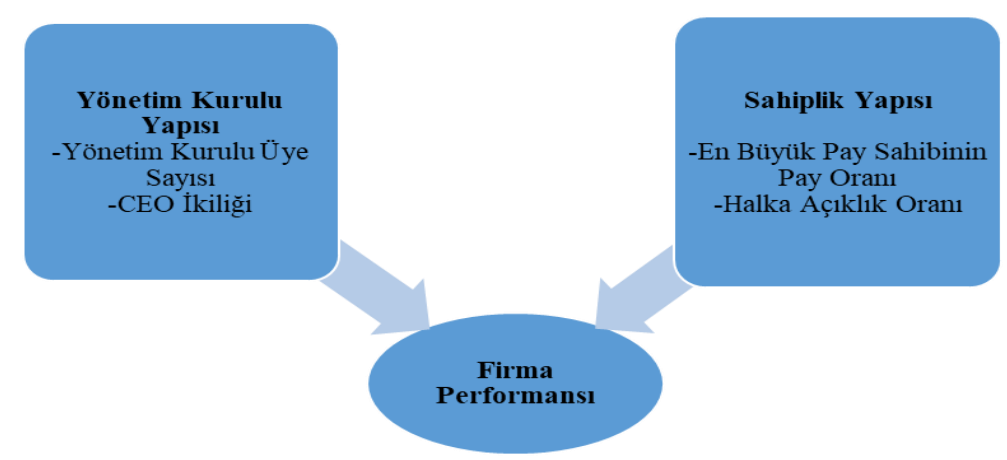


$\mathrm{Bu}$ çalışmada, BIST İmalat Sanayi Sektöründe faaliyet gösteren ve firmanın pay senetlerinin büyük bir çoğunluğunun bir aile tarafından yönetildiği yani sahiplik yoğunluğunun fazla olduğu firmaların yönetim kurulu ve sahiplik yapılarının finansal performans üzerindeki etkisini ölçmek amaçlanmaktadır. Çalışmada kullanılan en büyük pay sahibinin pay oranı, halka açıklık oran1, yönetim kurulu üye sayısı, CEO ikiliğinin ve kaldıraç ve satışların logaritması kontrol değişkenlerinin finansal performans göstergeleri olan aktif karlılık, özsermaye karlılığı, satışların karlılığı, Tobin-Q ve piyasa değeri logaritmasi üzerindeki etkisi panel veri regresyon analizi kullanılarak ortaya konulmak istenmiştir.

\section{Literatür Taraması}

Literatürde yönetim kurulu ve sahiplik yapısının firmaların finansal performansı üzerindeki etkisi farklı açılardan incelenmiştir. Yönetim kurulu ve sahiplik yapısı farklı finansal performans göstergeleri kullanılarak gerçekleştirilen çalışmalarla ilgili literatür özeti aşağıda sunulmuştur.

Sahiplik yapısı ve finansal performans arasındaki ilişkiyi araştıran ilk çalışma 1932 yılında Berle ve Means tarafından kaleme alınmıştır. Berle ve Means (1932), sahiplik yapısı ve firma performansı arasında negatif yönlü bir ilişkinin olması gerektiğini ifade etmişlerdir. Çalışmaya göre, sahiplik yüzdesi arttıkça profesyönel yöneticilerin kontrolü azalmakta, bu durum finansal performansı olumsuz yönde etkilemektedir. Buna karşın Demsetz ve Lehn (1985) firmaların sahiplik seviyesinin içsel faktörler ile belirlendiğini, birbirinden bağımsız olduğunu ve aralarında bir ilişkininin olmadığını ifade etmiş̧lerdir. Ayrıca yazarlar, sahiplik yapısının içsel faktörler tarafından belirlendiğini ifade etmişlerdir. McConnel ve Servaes (1990), 1976 yılındaki 1.173 ve 1986 yılındaki 1.093 firmadan bir örneklem oluşturarak sahiplik yapısı ve Tobin-Q oranı arasındaki ilişkiyi incelemişlerdir. Firmanın içindekilere ait pay senetleri ile Tobin-Q arasında eğrisel (curvilinear) anlamlı bir ilişki bulmuşlardır. İçsel sahipliğin düşük seviyede olduğu firmalarda ilişki kuvvetli bir şekilde pozitiftir. İçsel sahipliğin yüksek seviyede olduğu firmalarda Tobin-Q ve içsel sahiplik ilişkisi negatiftir. Genel olarak çalışmalarında, sahiplik yapısı ve finansal performans arasındaki ilişkinin doğrusal olmadığı sonucuna ulaşmışlardır.

Xu ve Wang (1999), Çin'de faaliyet gösteren halka açık firmaların sahiplik yapısı ile finansal performans arasındaki ilişkiyi çalışmalarında incelemişlerdir. Sahiplik yapısı olarak yoğunlaşmış sahiplik yapısının alındığı çalışmada, finansal performansı belirlemek için $\mathrm{PD} / \mathrm{DD}$, özsermaye karlılığı ve aktif karlılık oranı kullanılmıştır. Araştırma bulgularında pay senedi sahiplik yoğunluğu ile finansal performans arasında ilişkinin olduğunu tespit etmişlerdir. Bu çalışma gibi genel anlamda firmaların sahiplik yoğunluğu ile finansal performans1 göstergeleri arasında negatif veya pozitif yönde bir ilişkinin olduğunu Gürsoy ve Aydoğan (1999), Thomsen ve Pedersen (2000), Mitton (2002), Gönenç (2006), Kapopoulos ve Lazeretou (2007), Cheng (2008), Tanrı̈ver ve Aksoy (2010), Şamiloğlu ve Ünlü (2010), Mandacı ve Gümüş (2010), Fazlzadeh vd. (2011), Riewsathiratham vd. (2011), Işık ve Soykan (2013), Aytekin ve İbiş (2014), Tükenmez vd. (2016) çalışmaları ile desteklenmiştir.

Yurtoğlu'nun (2000) Türkiye'deki 305 halka açık firmayı incelediği çalışmada aile sahipliği ile firmanın finansal performansı arasında bir ilişkinin olduğunu bulgulamıştır. 
Türkiye ve farklı ülkelerde yapılan çalışmalarda aile sahiplik yapısı ile finansal performans arasında bir ilişkinin olduğu ve olmadığı çalışmalar bulunmaktadır. Bunlar, Xu ve Wang (1999), Andres (2008), Akman vd. (2015) çalışmalarıdır.

Gündüz ve Tatoğlu (2003), çalışmalarında yabancı sahiplik yapısı ile finansal performans arasındaki ilişkiyi araştırmıştır. Araştırmaları sonucunda, yabancı sahiplik yapısının finansal performansı etkilediğine ulaşmışlardır. Bu sonuç ile aynı sonucu elde eden veya ilişkinin olmadığını ifade eden çalışmalar, Aydın vd. (2007), Dwivedi ve Jain (2007), Arouri vd. (2011) ve Akman vd. (2015) tarafından yapılmıştır.

Thomsen ve Pedersen (2000) çalışmalarında sahiplik yapısı devlet olan firmaların finansal performans üzerinde etkisinin olduğunu ifade etmişlerdir. Devlet sahipliği ile finansal performans ilişkisi Estrin ve Rosevar (1999), Daqing vd. (2000), Gençtürk ve Usul (2003), Şamiloğlu ve Ünlü (2010), Erdoğan (2017) tarafından da araştırılmıştır.

McConnel ve Serveas (1990) çalışmalarında yönetici sahipliğinin finansal performans üzerindeki etkisinin olduğunu tespit etmiştir. Yönetici sahipliği ile finansal performans arasındaki ilişki Jensen ve Mecking (1976), Morck vd. (1988), Damanpaur ve Chaganti ve (1991), Demsetz ve Villalango (2001), Lemmon ve Lins (2003), Hiraki vd. (2003), Bulut vd. (2009), Aydın vd. (2007), Ünlü vd. (2011) tarafindan incelenmiştir.

Arora ve Sharma (2016), çalışmalarında yönetim kurulu yapısının belirlenmesinde kullanılan yönetim kurulu üye sayısı ve CEO ikiliğinin firma performansı üzerinde etkisinin olduğunu bulgulamışlardır. Yönetim kurulu üye sayısı ve CEO ikiliğinin firma performansı üzerindeki etkisinin anlamlı olduğu Rouf (2012), Lappalianen ve Niskaen (2012), Kılıç (2014), Acaravcı (2015), Doğan ve Topal (2015), Le ve Thi (2016), Karoğlu (2016) tarafından da tespit edilmiştir.

\section{Araştırmanın Amacı Ve Veri Seti}

Bu çalışmanın amacı, 2003-2014 yılları arasında BIST İmalat Sanayi Sektöründe yer alan ve pay senetlerinin çoğunluğunun bir aileye ait olduğu firmaların yönetim kurulu ve sahiplik yapısının finansal performans göstergeleri üzerindeki etkisini ölçmektir. Firmaların finansal performansını muhasebe ve piyasa temelli performans göstergeleri ile ölçülmüştür. Firmaların yönetim kurulu ve sahiplik yapısı çeşitli performans oranları ile karşılaştırılarak istatistiksel olarak ilişkisi belirlenmeye çalışmıştır.

Araştırmanın analizinde 2003-2014 yılları arasında BIST'de faaliyet gösteren ve verilerine kesintisiz ulaşılan pay senetlerinin çoğunun aileye ait olduğu 78 imalat firmaların yıllık verileri kullanılmıştır. Veriler Eviews 8 paket programı ile analiz edilmiştir.

Araştırmadaki 78 aile firmasının 11 adedinin Dokuma, Giyim Eşyası ve Deri Sanayi Sektöründe, 12 adedinin Gıda, İçki ve Tütün sektöründe, 7 adedinin Kağıt ve Kağıt Ürünleri, Basım ve Yayın Sanayi Sektöründe, 10 adedinin Kimya, Petrol, Kauçuk ve Plastik Ürünler Sanayi Sektöründe, 21 adedinin Metal Eşya, Makine ve Gereç Yapım Sanayi Sektöründe ve 17 adedinin Taş ve Toprağa Dayalı Sanayi Sektöründe faaliyet gösterdiği bilgisine ulaşılmıştır. 
Tespit edilen bu firmaların 2008 ve öncesi mali tablolarına ve faaliyet raporlarına BIST'in resmi web sayfasından (www.borsaistanbul.com), 2009 ve sonrasina ise Kamu Aydınlatma Platformu resmi web sayfasından (www.kap.gov.tr) yararlanılmış, ayrıca, firmaların kendi web sayfalarında yayınladıkları faaliyet raporlarından gerekli verilere ulaşılmıştır.

Analizde kullanılan bağımsız değişkenler; en büyük pay sahibinin pay oranı, halka açıklık oranı, yönetim kurulu üye sayısı ve CEO ikiliğinden oluşurken; bağımlı değişkenler muhasebe temelli performans göstergesi aktif karlılık, özsermaye karlılı̆̆1 ve satışların karlılı̆̆ından ve piyasa temelli performans göstergesi Tobin-Q ve piyasa değerinden oluşmaktadır. Analizde kullanılan bağımlı ve bağımsız değişkenler ve hesaplanma yöntemleri Tablo 1'de gösterilmektedir.

Tablo 1. Değişkenler ve hesaplanma yöntemleri

\begin{tabular}{|c|c|c|}
\hline Değişkenler & Hesaplanma Yöntemi & Sembolü \\
\hline \multicolumn{3}{|l|}{ Bağımlı Değişkenler } \\
\hline Aktif Karlılık & Net Kar/Toplam Aktif & ROA \\
\hline Özsermaye Karlılığı & Net Kar/Özsermaye & ROE \\
\hline Satışların Karlılığı & Net Kar/Toplam Net Satışlar & ROS \\
\hline Tobin Q & Piyasa değeri/Aktif Büyüklüğü & TOBİNQ \\
\hline Piyasa Değeri & Piyasa Değerinin Logaritması & LPIYASA \\
\hline \multicolumn{3}{|l|}{ Bağımsız Değişkenler } \\
\hline $\begin{array}{l}\text { En Büyük Pay Sahibinin Pay } \\
\text { oranı }\end{array}$ & $\begin{array}{l}\text { En Büyük Pay Sahibinin Sermaye } \\
\text { Tutary/Toplam Özsermaye }\end{array}$ & EBH \\
\hline Halka Açıklık Oranı & $\begin{array}{l}\text { Halka Açık Sermaye Tutarı/Toplam } \\
\text { Özsermaye }\end{array}$ & HAO \\
\hline Yönetim kurulu Büyüklüğü & $\begin{array}{l}\text { Yönetim kurulunda bulunan } \\
\text { sayısının logaritması }\end{array}$ & LYKS \\
\hline CEO İkiliği & $\begin{array}{l}\text { Genel müdürün aynı zamanda yönetim } \\
\text { kurulu üyesi olması durumunda 1, } \\
\text { dişarıdan bir CEO olması } 0 \text { ile ifade } \\
\text { edilmektedir. (Dummy Değişkeni) }\end{array}$ & CEOD \\
\hline \multicolumn{3}{|l|}{ Kontrol Değişkenleri } \\
\hline Satışların Büyüklüğü & Net Satışların Logaritması & LSATIS \\
\hline Kaldıraç Oranı & Toplam borç/Toplam Aktif & LEV \\
\hline
\end{tabular}

\section{Yöntem Ve Bulgular}

Yönetim kurulu yapısı ve sahiplik yapısının firma performansı üzerindeki etkisini ortaya koymak için panel veri analizinden yararlanılmıştır. Panel veri analizi, aynı yatay kesit $(\mathrm{N})$ için iki ya da daha fazla zaman dönemindeki (T) gözlemlerden oluşmaktadır (Stock ve Watson, 2011:352). Kisacas1 panel veri analizi Green (2003) tarafindan zaman serileri ve yatay kesit verilerinin bir arada kullanıldığı analizler şeklinde tanımlanmıştır.

Panel veri regresyon yönteminde, havuzlanmış EKK modeli, sabit etki modeli ve rassal etki modeli olmak üzere üç model bulunmaktadır. Bu modellerden havuzlanmış EKK modelinde, hem sabit hem de eğim katsayılarının yatay kesite ve zamana göre sabit olduğu 
varsayılmaktadır. Bir başka ifadeyle, bu modelde bütün gözlemlerin homojen olduğu düşünülmektedir. $\mathrm{Bu}$ varsayım altında oluşan panel veri regresyon modeli (Tatoğlu, 2012:40);

$$
Y_{i t}=\beta_{0}+\sum_{k=1}^{K} \beta_{k} X_{k i t}+u_{i t}
$$

şeklinde ifade edilmektedir. Sabit etki modeli, panel veriden dişlanan değişkenlerin yatay kesit boyutunun değiştiği, zaman boyutunun değişmediği durumlarda kullanılan bir yöntemdir. Sabit etkiler regresyon modeli, her mevcut yatay kesit için bir tane olmak üzere $n$ tane farklı kesit katsayısına sahiptir. Bu kesit katsayıları bir ikili değişken setiyle temsil edilmektedir. Bu ikili değişkenlerden biri yatay kesitler arasında değişenlerin; diğer değişken ise zaman içinde sabit olan dışlanan bütün değişkenlerin etkilerini içine almaktadır (Stock ve Watson, 2011:358). Bu çerçevede sabit etki regresyon modeli aşağıdaki gibi hesaplanmaktadır:

$$
Y_{i t}=\beta_{0}+\beta_{1} X_{i t}+\beta_{2} \mu_{i}+u_{i t}
$$

$\mathrm{Bu}$ modelde $\mu_{i}$, yatay kesitten yatay kesite değișen ancak zamana bağlı olarak değişmeyen sabit etki değişkenini ifade etmektedir. $Y_{i t}$ bağımlı değişkeni, $X_{i t}$ bağımsız değişkeni, $\beta_{1}$ parametre tahminini ve $u_{i t}$ hata terimini göstermektedir.

Rassal etki modelinde, birim etkiler sabit olmadığından dolayı sabit parametre içerisinde değildir ve tesadüfidir. Model tesadüfi olduğu içinde hata payı içerisinde yer almaktadır. Havuzlanmış EKK gibi, Rassal Etki modelinde hata terimi için $u_{i t}$ değişkeni modele dahil edilmektedir (Wooldridge, 2002:257). Ayrıca, modele birim hata eklenmektedir. Bu nedenle, hata terimi $u_{i t}+\mu_{i t}$ den oluşmakta ve modelde $u_{i t}$ artık hataları ve $\mu_{i t}$ birim hatayı göstermektedir (Tatoğlu, 2012:104). Bu çerçevede oluşan rassal etki regresyon modeli:

$$
Y_{i t}=\beta_{0}+\sum_{k=1}^{K} \beta_{k i} X_{k i t}+\left(u_{i t}+\mu_{i t}\right)
$$

şeklinde kurulmaktadır. $\mathrm{Bu}$ üç regresyon modelinden hangisinin kullanılması gerektiğini tahmin etmek için ise $\mathrm{F}$ testi, Breush Pagan LM testi ve Hausman testi yapılmaktadır.

F testi, analizde havuzlanmış EKK modelinin mi yoksa sabit etki modelinin mi yapılmasına karar vermek için yapılan bir testtir. Baltagi'nin (2014), F testi hipotez sınaması;

$$
H_{0}: \beta_{i}=\beta \text { (Havuzlanmış EKK modeli Etkindir) }
$$

şeklindedir. Breush Pagan LM testi, havuzlanmış EKK modeli ve rassal etki modelinden hangisinin uygun bir yöntem olduğunu belirlemek için yapılmaktadır. LM testi ile modelin bireysel heterojenliğinin varlığını sınamış ve kalıntılarına dayanarak 
geliştirilmiştir. Bu test aynı zamanda 1 serbestlik derecesi ile $\chi^{2}$ dağılımına uygundur (Tatoğlu, 2012:172-173). Bu testin hipotez sinaması;

\section{$H_{0}: \sigma_{\mu}^{2}=0$, (Havuzlanmış EKK modeli uygundur)}

şeklindedir. Eğer F testi ve Breush Pagan LM testi sonuçlarına göre havuzlanmış EKK'nın model için uygun olmayan bir test olduğuna karar verilirse Hausman testi yapilmaktadır. Hausman testi ile sabit etki ve rassal etki modelinden hangisinin tercih edileceği belirlenmektedir. $\mathrm{Bu}$ test ile sabit etki modelinin tutarlı ve yansız olduğu varsayımından yola çıkılmaktadır (Baltagi, 2005:66). Rassal etkiler tahmincisinin geçerli olduğu şeklinde kurulan hipotezi, $\mathrm{k}$ serbestlik dereceli $\chi^{2}$ dağılımına uyan istatistik ile test etmektedir (Tatoğlu, 2012:180). Bu çerçevede kurulan Hausman hipotez sınaması aşağıdaki gibidir:

\section{$H_{0}$ : Açılklayıcı değiş̧ken ve birim etkileri arasında korelasyon yoktur.}

Çalışmamızda kurulan modeller ise aşağıdaki gibidir:

$$
\begin{gathered}
R O A_{i t}=\alpha_{i t}+\beta_{1} A_{S O} O_{i t}+\beta_{2} H A O_{i t}+\beta_{3} L Y K S_{i t}+\beta_{4} C E O D_{i t}+\beta_{5} L E V_{i t}+\beta_{6} L_{S A T I S}+\varepsilon_{i t} \\
\mathrm{i}=1, \ldots \mathrm{N} ; \mathrm{t}=1, \ldots \mathrm{T}
\end{gathered}
$$

(1)

$$
\begin{gathered}
R O E_{i t}=\alpha_{i t}+\beta_{1} A_{S O O_{i t}}+\beta_{2} H A O_{i t}+\beta_{3} L Y K S_{i t}+\beta_{4} C E O D_{i t}+\beta_{5} L E V_{i t}+\beta_{6} L S A T I S_{i t}+\varepsilon_{i t} \\
\mathrm{i}=1, \ldots \mathrm{N} ; \mathrm{t}=1, \ldots \mathrm{T}
\end{gathered}
$$

(2)

$$
\begin{gathered}
\operatorname{ROS}_{i t}=\alpha_{i t}+\beta_{1} \text { ASO }_{i t}+\beta_{2} H A O_{i t}+\beta_{3} L Y K S_{i t}+\beta_{4} C E O D_{i t}+\beta_{5} L E V_{i t}+\beta_{6} L S A T I S_{i t}+\varepsilon_{i t} \\
\mathrm{i}=1, \ldots \mathrm{N} ; \mathrm{t}=1, \ldots \mathrm{T}
\end{gathered}
$$

(3)

$$
\begin{aligned}
& \text { Tobin }-Q_{i t}=\alpha_{i t}+\beta_{1} A_{S O} O_{i t}+\beta_{2} H_{A O O_{i t}}+\beta_{3} L Y K S_{i t}+\beta_{4} C E O D_{i t}+\beta_{5} L E V_{i t}+ \\
& \beta_{6} L_{S A T I S}+\varepsilon_{i t} \\
& \quad \mathrm{i}=1, \ldots \mathrm{N} ; \mathrm{t}=1, \ldots \mathrm{T} \\
& \text { LPIYASA }_{i t}=\alpha_{i t}+\beta_{1} \text { ASO }_{i t}+\beta_{2} \text { HAO }_{i t}+\beta_{3} L Y K S_{i t}+\beta_{4} C_{E O D_{i t}}+\beta_{5} L E V_{i t}+\beta_{6} \text { LSATIS }_{i t}+ \\
& \varepsilon_{i t} \quad \mathrm{i}=1, \ldots \mathrm{N} ; \mathrm{t}=1, \ldots \mathrm{T}
\end{aligned}
$$

Kurulan bu modellerde görüldüğü gibi finansal performans için toplu bir model değil her bir bağımsız değişken için ayrı ayrı model kurulmuştur. Bunun nedeni, daha önce yapılan bazı çalışmalarda görülen çoklu doğrusallık problemidir (Aytekin ve İbiş, 2014; Konak ve Kendirli, 2013:18). Çoklu doğrusallık problemi yaşanmasının nedeni ise araştırmada kullanılan firmaların sahiplik yapılarının ve yönetim kurullarının bazı dönemlerde değişmemesinden kaynaklanmaktadır. Bu nedenle, analizin açıklanma gücünü artırmak için 
finansal performans değişkenlerinin her biri ile regresyon modeli kurulmaktadır (Konak ve Kendirli, 2015:128).

Çalışmada regresyon analizlerinden önce 78 aile firmasının 12 yıllık verileri içeren temel istatistik sonuçları tanımlayıcı istatistik ile analiz edilmiştir. Bu kapsamda elde edilen tanımlayıcı istatistik sonuçları Tablo 2'de verilmiştir.

Tablo 2. Tanımlayıcı istatistik

\begin{tabular}{lccccc}
\hline Değişkenler & $\boldsymbol{N}$ & Minimum & Maksimum & Ortalama & Std. Sapma \\
\hline ROA & 936 & $-0,60$ & 0,47 & 0,04 & 0,09 \\
ROE & 936 & $-16,55$ & 4,24 & 0,02 & 0,68 \\
ROS & 936 & $-1,52$ & 0,53 & 0,03 & 0,13 \\
LPIYASA & 936 & $-4,47$ & 82,84 & 14,93 & 4,81 \\
TOBİNQ & 936 & $-57,59$ & 141,73 & 1,76 & 12,40 \\
LEV & 936 & 0,02 & 1,88 & 0,45 & 0,27 \\
LSATIS & 936 & 12,78 & 23,13 & 18,71 & 1,52 \\
ASO & 936 & $-3,10$ & 13,71 & 0,23 & 0,61 \\
HAO & 936 & $-2,07$ & 7,25 & 0,16 & 0,42 \\
YKB & 936 & 3,000 & 17,00 & 6,72 & 2,21 \\
CEOD & 936 & 0,000 & 1,000 & 0,57 & 0,49 \\
\hline
\end{tabular}

Tablo 2'ye göre, 2003-2014 yılları arasında BIST İmalat Sanayi Sektörü'ne kayıtlı 78 aile firmasının 936 gözlemden en düşük ortalamaya sahip olan değişkenin ROE, en yüksek ortalamaya sahip değişkenin satışların logaritması olduğu görülmüştür. En düşük standart sapmaya sahip olan değişkenin ROA, en yüksek standart sapmaya sahip olan değişkenin ise Tobin-Q oranı olduğuna ulaşılmıştır. Minimum ve maksimum değere bakıldığında aralarında en yüksek farka sahip olan değişkenin Tobin-Q olduğu saptanmıştır.

Tanımlayıcı istatistiklerden sonra hangi panel veri regresyon modelinin kurulan modeller için uygun olduğuna karar veren testlere geçilmiştir. İlk olarak kurulan beş modelin F testi istatistik değerleri sonuçlarına yer verilmiştir.

Tablo 3. F testi sonuçları

\begin{tabular}{lllll}
\hline \multicolumn{2}{l}{ Model 1 } & & & \\
\hline Test & F İstatistiği & Olasılık & Sıfır Hipotezi & Karar \\
\hline F & $4,801^{*}$ & 0,0000 & Havuzlanmış EKK Modeli Etkindir. & Red \\
\hline Model 2 & & & \\
\hline Test & F İstatistiği & Olasılık & Sıfır Hipotezi & Karar \\
\hline F & $1,5908^{*}$ & 0,0015 & Havuzlanmış EKK Modeli Etkindir. & Red \\
\hline Model 3 & & & \\
\hline Test & F İstatistiği & Olasılık & SIfır Hipotezi & Karar \\
\hline F & $2,9823^{*}$ & 0,000 & Havuzlanmış EKK Modeli Etkindir. & Red \\
\hline Model4 & & & \\
\hline Test & F İstatistiği & Olasılık & SIfır Hipotezi & Karar \\
\hline F & $7,1521^{*}$ & 0,0000 & Havuzlanmış EKK Modeli Etkindir. & Red \\
\hline Model 5 & & & \\
\hline Test & F İstatistiği & Olasılık & SIfır Hipotezi & Karar \\
\hline F & $10,0997^{*}$ & 0,0000 & Havuzlanmış EKK Modeli Etkindir. & Red \\
\hline
\end{tabular}

Not: Olasılık değerine göre *, \%1 anlamlılık düzeyini ifade etmektedir. 
F testi istatistik sonuçlarına göre, "Havuzlanmış EKK modeli etkindir" sıfır hipotezi tüm modellerde reddedilmiştir. Başka bir ifadeyle, çalışmada kurulan modellerin havuzlanmış EKK yöntemi için uygun olmadığını buna karşın sabit etki modelinin analiz edilmesinin daha uygun olabileceği sonucuna ulaşılmıştır.

$\mathrm{F}$ testinden sonra yapılması gereken bir diğer test Breush-Pagan LM testidir. Bu testin sonuçları aşağıdaki Tablo 4'de açıklanmıştır.

Tablo 4. Breusch Pagan LM testi sonuçları

\begin{tabular}{|c|c|c|c|c|}
\hline \multicolumn{5}{|c|}{ Model 1} \\
\hline & $\chi^{2}$ İstatistiği & Olasılık & Sifur Hipotezi & Karar \\
\hline & $245,717^{*}$ & 0,0000 & Havuzlanmış EKK Modeli Uygundur & Red \\
\hline \multicolumn{5}{|c|}{ Model 2} \\
\hline Test & $\chi^{2}$ İstatistiği & Olasılık & SIfır Hipotezi & Karar \\
\hline & $4,617 * *$ & 0,0316 & Havuzlanmış EKK Modeli Uygundur & Red \\
\hline \multicolumn{5}{|c|}{ Model 3} \\
\hline Test & $\chi^{2}$ İstatistiği & Olasilık & Sifir Hipotezi & Karar \\
\hline & $68,6268^{*}$ & 0,0000 & Havuzlanmış EKK Modeli Uygundur & Red \\
\hline \multicolumn{5}{|c|}{ Model 4} \\
\hline Test & $\chi^{2}$ İstatistiği & Olasilık & Sifir Hipotezi & Karar \\
\hline LM & $559,7019^{*}$ & 0,0000 & Havuzlanmış EKK Modeli Uygundur & Red \\
\hline \multicolumn{5}{|c|}{ Model 5} \\
\hline Test & $\chi^{2}$ İstatistiği & Olasilık & Sifir Hipotezi & Karar \\
\hline LM & $647,761 *$ & 0,0000 & Havuzlanmış EKK Modeli Uygundur & Red \\
\hline
\end{tabular}

Tablo 4 sonuçlarına göre modellerin katsayı anlamlılık düzeyi \%5'ten küçük olduğu için sıfır hipotezi reddedilmiştir. Diğer bir ifadeyle, havuzlanmış EKK modeli çalışmamızda kurulan modeller için uygun olmadığı sonucuna ulaşılmıştır. Ayrıca, kurulan modellerde zaman ve/veya yatay kesit etkilerinin olduğu görülmektedir.

Bütün modeller için yapılan iki test sonucuna göre havuzlanmış EKK testi kurulan modeller için uygun bir analiz değildir. Bundan dolayı, sabit etki ve rassal etki modellerinden hangisinin tercih edilmesi gerektiğini belirleyen Hausman testi yapılmıştır. Tablo 5'de kurulan beş modelin Hausman testi sonuçları yer almaktadır.

Tablo 5. Hausman testi sonuçları

\begin{tabular}{llllc}
\hline Model 1 & & & & \\
\hline Test & $\begin{array}{l}\text { Hausman } \\
\text { İstatistiği }\end{array}$ & Olasılık & Sıfır Hipotezi & Karar \\
\hline Hausman & $19,6426^{*}$ & 0,0032 & $\begin{array}{l}\text { Açıklayıcı Değişken ve Birim Etkileri } \\
\text { Arasında Korelasyon yoktur. }\end{array}$ & Red \\
\hline Model 2 & & & & Karar \\
\hline Test & $\begin{array}{l}\text { Hausman } \\
\text { İstatistiği }\end{array}$ & Olasılık & Sıfır Hipotezi & Red \\
\hline Hausman & $60,2486^{*}$ & 0,0000 & $\begin{array}{l}\text { Açıklayıcı Değişken ve Birim Etkileri } \\
\text { Arasında Korelasyon yoktur. }\end{array}$ & \\
\hline Model 3 & & & & Karar \\
\hline Test & $\begin{array}{l}\text { Hausman } \\
\text { İstatistiği }\end{array}$ & Olasılık & Sıfır Hipotezi & \\
\hline
\end{tabular}


Kılıç ve Ayrıçay / Yönetim Kurulu ve Sahiplik Yapısının Finansal Performans Üzerindeki Etkisi: BIST İmalat Sanayi Sektöründe Bir Alan Araştırmas1 / Impact of the Board of Directors and Ownership Structure on Financial Performance: A Field Study in BIST Manufacturing Industry

\begin{tabular}{llllc}
\hline Hausman & $26,8188^{*}$ & 0,0002 & $\begin{array}{l}\text { Açıklayıcı Değişken ve Birim Etkileri } \\
\text { Arasında Korelasyon yoktur. }\end{array}$ & Red \\
\hline Model4 & & & & Karar \\
\hline Test & $\begin{array}{l}\text { Hausman } \\
\text { İstatistiği }\end{array}$ & Olasılık & Sıfır Hipotezi & Red \\
\hline Hausman & $15,8832^{*}$ & 0,0315 & $\begin{array}{l}\text { Açıklayıcı Değişken ve Birim Etkileri } \\
\text { Arasında Korelasyon yoktur. }\end{array}$ & \\
\hline Model 5 & & & & Karar \\
\hline Test & $\begin{array}{l}\text { Hausman } \\
\text { İstatistiği }\end{array}$ & Olasılık & Sıfır Hipotezi & Red \\
\hline Hausman & $27,3180^{*}$ & 0,0001 & $\begin{array}{l}\text { Açılayıcı Değişken ve Birim Etkileri } \\
\text { Arasında Korelasyon yoktur. }\end{array}$ & \\
\hline
\end{tabular}

Not: * ve ** sırasıyla \%1 ve \%5 katsayı anlamlılık düzeyini göstermektedir.

Tablo 5'deki Hausman testi sonuçlarına göre, kurulan beş model için en uygun yöntem sabit etki regresyon modeli olduğu tespit edilmiştir. Bu çerçevede yapılan sabit etki regresyon modeli sonuçları Tablo 6'da yer almaktadır.

Tablo 6. Sabit etki regresyon analizi sonuçları

\begin{tabular}{|l|c|c|c|c|c|}
\hline Değişkenler & ROA & ROE & ROS & Tobin-Q & $\begin{array}{l}\text { Piyasa } \\
\text { Değeri }\end{array}$ \\
\hline EBH & $-0,0287^{*}$ & $-0,1953^{*}$ & $-0,0156^{* *}$ & $0,0847^{*}$ & $0,6106^{*}$ \\
& 0,0007 & 0,0000 & 0,0141 & 0,0000 & 0,0063 \\
\hline HAO & $0,0512^{*}$ & $0,0195^{*}$ & $0,0121^{* *}$ & $-0,0301^{* *}$ & $-0,5716^{* * *}$ \\
& 0,0002 & 0,0422 & 0,0479 & 0,0215 & 0,0847 \\
\hline LYKS & $0,0164^{* *}$ & 0,0270 & $0,0185^{* * *}$ & $0,1968^{*}$ & $0,8692^{* *}$ \\
& 0,0394 & 0,1995 & 0,0847 & 0,0019 & 0,0233 \\
\hline CEOD & $-0,0247^{*}$ & $-0,0023^{* *}$ & $-0,0136^{*}$ & $-0,0347^{* *}$ & $-0,6224^{*}$ \\
& 0,0296 & 0,0662 & 0,0135 & 0,0657 & 0,0129 \\
\hline LEV & $-0,1589^{*}$ & $-0,1117^{*}$ & $-0,1842^{*}$ & $-0,1373^{*}$ & $-1,4064^{*}$ \\
& 0,0000 & 0,0000 & 0,0000 & 0,0000 & 0,0020 \\
\hline LSATIS & $0,0119 * *$ & $0,0207^{*}$ & $0,0211^{*}$ & $-0,0334^{*}$ & $0,5194^{*}$ \\
& 0,0384 & 0,0000 & 0,0050 & 0,0001 & 0,0000 \\
\hline SABIT & $-0,0738$ & $-0,2794^{*}$ & $-0,2341^{* *}$ & $-0,8540^{*}$ & $6,0101^{*}$ \\
& 0,5013 & 0,0000 & 0,0893 & 0,0001 & 0,0063 \\
\hline $\boldsymbol{R}^{2}$ & 0,5308 & 0,2528 & 0,5925 & 0,4755 & 0,9062 \\
\hline Düzeltilmiş & 0,4794 & 0,2475 & 0,5479 & 0,4170 & 0,8952 \\
$\boldsymbol{R}^{2}$ & & & & & \\
\hline F Testi & $10,3315^{*}$ & $47,1014^{*}$ & $13,2798^{*}$ & $8,1375^{*}$ & $82,9245^{*}$ \\
& 0,0000 & 0,0000 & 0,0000 & 0,0000 & 0,0000 \\
\hline Durbin- & 1,8246 & 1,8838 & 1,7521 & 1,5645 & 1,6040 \\
Watson & & & & & \\
\hline
\end{tabular}

Not: ${ }^{*}, * *$ ve $* * *$ sirasıyla $\% 1, \% 5$ ve $\% 10$ katsayı anlamlılık düzeyini göstermektedir.

Tablo 6'da oluşturulan panel regresyon modelleri bağımsız değişkenler EBH, HAO, LYKS ve CEOD ile kontrol değişkenleri LEV ve LSATIS'ın sırayla bağımsız değişkenler olan ROA, ROE, ROS, Tobin-Q ve LPIYASA ile analiz sonuçları gösterilmiştir. Bu tabloda yer alan regresyon tahminlerinde $\mathrm{F}$ değerinin beş model için istatistiksel olarak anlamlı olduğu görülmektedir. 
Birinci modelde, aktif karlılı (ROA) ile en büyük pay sahibinin pay oranı $(0.01$ anlamlılık düzeyinde), CEO ikiliği (0.05 anlamlılık düzeyinde) ve kaldıraç oranı (0.01 anlamlılık düzeyinde), arasında istatistiksel olarak anlamlı ve negatif bir ilişki vardır. Ancak, halka açıklık oranı (0.01 anlamlılık düzeyinde), yönetim kurulu üye sayısı logaritması ( 0.05 anlamlılık düzeyi) ve satışların logaritması ( 0.05 anlamlılık düzeyinde) ile anlamlı ve pozitif bir ilişki olduğu bulgulanmıştır.

İkinci modelde, özsermaye karlılığ ile halka açıklık oranı $(0.05$ anlamlılık düzeyinde) ve satışların logaritması (0.01 anlamlılık düzeyinde) arasında pozitif ve istatistiksel olarak anlamlı bir ilişki bulunmuştur. En büyük pay sahibinin pay oranı $(0.01$ anlamlılık düzeyinde), CEO ikiliği (0.10 anlamlılık düzeyinde) ve kaldıraç oranı (0.01 anlamlılık düzeyinde) ile özsermaye karlılığ yönde bir ilişki olduğuna ulaşılmıştır. Ancak yönetim kurulu üye sayısı ile özsermaye karlılığı arasında istatistiksel olarak anlamsız bir ilişki olduğu bulgulanmıştır.

Üçüncü modelde, en büyük pay sahibinin pay oranı (0.05 anlamlılık düzeyinde), CEO ikiliği (0.01 anlamlılık düzeyinde) ve kaldıraç oranı (0.01 anlamlılık düzeyinde) ile satışların karlılı̆ğ arasında negatif yönlü ve istatistiksel olarak anlamlı ilişki olduğu bulgulanmıştır. Ancak, satışların karlılığı ile halka açıklık oranı (0.05 anlamlılık düzeyinde), CEO ikiliği (0.01 anlamlılık düzeyinde) ve kaldıraç oranı (0.01 anlamlılık düzeyinde) istatistiksel olarak anlamlı ve pozitif yönlü bir ilişki olduğu tespit edilmiştir.

Piyasa temelli performans göstergesi olan Tobin-Q ile kurulan dördüncü modelde, Tobin-Q ile EBH (0.01 anlamlılık düzeyinde) ve LYKS (0.01 anlamlılık düzeyinde) arasında istatistiksel olarak anlamlı ve pozitif yönlü bir ilişkinin olduğuna ulaşılmıştır. HAO (0.05 anlamlılık düzeyinde), CEOD (0.10 anlamlılık düzeyinde), LEV (0.01 anlamlılık düzeyinde) ve LSATIS (0.01 anlamlılık düzeyinde) negatif yönlü ve istatistiksel olarak anlamlı bir ilişkinin olduğuna ulaşılmıştır.

Beşinci modelde ise piyasa değeri ile EBH (0.01 anlamll1ık düzeyinde), LYKS (0.10 anlamlılık düzeyinde) ve LSATIS (0.01 anlamlılık düzeyinde), arasında istatistiksel olarak anlamlı ve pozitif yönlü bir ilişkinin olduğu tespit edilmiştir. Piyasa değeri ile HAO $(0.10$ anlamlılık düzeyinde), CEOD (0.01 anlamlılık düzeyinde), LEV (0.01 anlamlılık düzeyinde), arasında negatif yönlü ve istatistiksel olarak anlamlı bir ilişki olduğu bulgulanmıştır.

Elde edilen sonuçlar göre, en büyük pay sahibinin pay oranındaki artış olmasının muhasebe temelli performans göstergelerini azaltacağının, piyasa temelli performans göstergelerini artıracağının öne sürdüğü çalışmaları (Gürsoy ve Aydoğan (1998), Yıldırım (2007), Bayramoğlu (2010), Önem ve Demir'in (2015)) doğrulamaktadır. Halka açıklık oranının ise muhasebe temelli performans göstergelerini pozitif; piyasa temelli performans göstergelerini negatif etkilendiği Önem ve Demir'in (2015), Yıldırım (2007), Bayrakdaroğlu (2010) tarafindan desteklenmektedir.

Yönetim kurulu üye sayısının artmasıyla finansal performansın artacağının önem sürüldüğü çalışmaların (Tanrı̈ver ve Aksoy (2010), Manaseer (2012), Acaravcı (2015)) sonuçları ile örtüşmektedir. Yönetim kurulu başkanı ile CEO'nun aynı kişi olması halinde finansal performansı azalacağının öne sürüldüğü çalışmaları (Kula (2006), Önem ve Demir (2015), Acaravcı vd. (2015), Arora ve Sharma (2016)) doğrulamaktadır. 


\section{Sonuc}

Yönetim kurulu ve sahiplik yapısı, firmaların en önemli iki kurumsal yönetim mekanizmalarındandır. Bu iki kurumsal yönetim mekanizmasının firmalar tarafindan uygulanması performanslarını etkilemektedir. Bu çalışmanın amacı da, BIST imalat sektöründe 2003-2014 yılları arasında faaliyet gösteren ve pay senetlerinin çoğunun bir ailenin elinde olduğu 78 firmanın sahiplik ve yönetim kurulu yapısının finansal performansına olan etkisini incelemektir. Çalışma kapsamında; yönetim kurulu yapısını yönetim kurulu üye sayısı logaritması (LYKS) ve CEO ikiliği (CEOD), sahiplik yapısını en büyük pay sahibinin pay oranı (EBH) ve halka açıklık oranı (HAO) bağımsız değişkenleri temsil ederken, bağımlı değişken olarak muhasebe temelli performans göstergesi olan aktif karlılık (ROA), özsermaye karlılığı (ROE), satışların karlılığı (ROS) ve piyasa temelli performans göstergeleri olan Tobin-Q oranı ve piyasa değeri logaritması (LPIYASA) kullanılmıştır. Modelin açıklama gücünü artırmak için ise kaldıraç oranı (LEV) ve satışların doğal logaritması (LSATIS) kontrol değişkeni olarak analize dahil edilmiştir.

Panel regresyon analizi sonucunda, en büyük pay sahibinin pay oranı muhasebe temelli performans göstergelerini istatistiksel olarak anlamlı ve negatif yönde etkilerken; piyasa temelli performans göstergelerini istatistiksel olarak anlamlı ve pozitif yönde etkilediğine ulaşılmıştır. Halka açıklık oranının ise muhasebe temelli performans göstergelerini istatistiksel olarak anlamlı ve pozitif etkilerken; piyasa temelli performans göstergeleri istatistiksel olarak anlamlı ve negatif yönde etkilemektedir.

Yönetim kurulu üye sayısı ile aktif karlılık, satışların karlılığı, Tobin-Q oranı ve piyasa değeri logaritması arasındaki ilişki istatistiksel olarak anlamlı ve pozitif iken, özsermaye karlılığına etkisi anlamsızdır. Yönetim kurulu üye sayısının finansal performans göstergelerini pozitif yönde etkilemesi kurumsal yönetim teorilerinden kaynak bağımlılığı teorisiyle açıklanabilir. Bu teoriye göre, kurul üye sayısının fazla olmasının daha fazla bilgi, daha yoğun tecrübe ve daha iyi tavsiye şeklinde bir takım avantajları olacaktır. Kaynak bağımlılı̆̆ı teorisine göre elde edilen bu avantajlar firmaların finansal performansını artırmaktadır.

Bir firmada CEO ikiliğinin olması ise firmanın finansal performansı istatistiksel olarak anlamlı ancak negatif yönde etkilemektedir. Elde edilen bu sonuç, kurumsal yönetim teorilerinden vekalet teorisi ile açıklanabilir. Vekalet teorine göre, bir firmada CEO ikiliğinin olması finansal performansı negatif yönde etkilemektedir. Yapılan regresyon analizi ile elde ettiğimiz bu sonucun en büyük nedenlerinden birisi olarak analizi yapılan firmaların aile firması olması ve CEO görevinin genellikle yönetim kurulu başkanı tarafından yürütülmesi olarak gösterilebilir.

Modelin açıklama gücünü gösteren kaldıraç oran1, finansal performans göstergelerini istatistiksel olarak anlamlı ve negatif yönde etkilemektedir. Bir diğer kontrol değişkeni olan satışların logaritması ise aktif karlılık hariç diğer finansal performans göstergeleri anlamlı ve pozitif yönde etkilemektedir.

Genel olarak ele alındığında, sahiplik yapısı ve yönetim kurulu yapısının finansal performans üzerindeki etkili olduğunu ifade edilebilir. Dolayısıyla firmalar finansal 
performanslarını artıırken sahiplik ve yönetim kurulu yapısını dikkate almaları gerektiği söylenebilir.

\section{Kaynakça}

Acaravc1, Kakilli S., Kandır, S., Y. ve Zelka, A. (2015). "Kurumsal Yönetimin BIST Şirketlerinin Performanslarına Etkisinin Araştırılması", Niğde Üniversitesi İktisadi ve İdari Bilimler Fakültesi Dergisi, 8(1):171-183.

Akman, Hoşal, N., Mugan, S. C. ve Akışık, O. (2015). "Ownerhsip Concentration Effect on Firm Performance in Turkey", Muhasebe Bilim Dünyası Dergisi, 17(1):33-56.

Andres, C. (2008). "Large Shareholders and Firm Performance-An Empirical Examination of Founding-Family Ownership", Journal of Corporate Finance, 14:431-445.

Ho, C.-A. ve Williams, M. S. (2003). "International Comparative Analysis of the Association Between Board Structure and The Efficiency of Value Added by a Firm From its Physical Capital and Intellectual Capital Resources", The International Journal of Accounting, 38:465-491.

Arora, A. ve Sharma, C. (2016). "Corporate Governance and Firm Performance in Developing Countries: Evidence From India", Corporate Governance: The International Journal of Business in Society, 16(2):420-436

Aydın, N.; Sayim, M. ve Yalama, A. (2007). "Foreign Ownership and Firm Performance: Evidence From Turkey", International Research Journal of Finance and Economics, 11:103-111.

Aytekin, S. ve İbiş, A. (2014). "Mülkiyet Yapısının İşletmelerin Finansal Performansı Üzerindeki Etkilerinin Değerlendirilmesi: BIST Metal Eşya, Makine Endeksi (XMESY) Üzerinde Bir Uygulama”, Dumlupınar Üniversitesi Sosyal Bilimler Dergisi, 40:119130.

Baltagi, B., H. (2005). Econometric Analysis of Panel Data, Third Edition, United Kingdom:John Wiley \& Sons.

Baltagi, B. H., (2014). Econometric Analysis of Panel Data, Fifth Edition, United Kingdom:John Wiley \& Sons.

Bayrakdaroğlu, A. (2010). "Mülkiyet Yapısı ve Finansal Performans: İMKB Örneği", Ekonomi Bilimleri Dergisi, 2(2):11-20.

Berle, A., A. ve Means, G. C. (1932). The Modern Corporate and Private Property, New York:Harcourt, Brace \&World.

Bulut, H. İ., Çankaya, F. ve Bünyamin, E. (2009). "Yönetici-Sahiplik Düzeyinin Halka Arz Sonrası Faaliyet Performans1 ve Düşük Fiyatlandırma Üzerine Etkisi: İMKB Örneği”, Gazi Üniversitesi İIBF Dergisi, 11(1):101-120.

Cheng, S. (2008). "Board Size and The Variability of Corporate Performance", Journal of Financial Economics, 87(1):1-26.

Damanpour, F. ve Ghanganti, R., (1991). "Institutional Ownership, Capital Structure and Firm Performance", Strategic Management Journal, 12:479-491.

Demsetz, H. ve Lehn, K. (1985). "The Structure of Corporate Ownership: Causes and Consequences" Journal of Political Economy, 93(6):1155-1177.

Demsetz, H. ve Villalonga, B. (2001). "Ownership Structure and Corporate Performance" Journal of Corporate Finance, 7:209-233.

Daqing, Q., Woody, W. ve Zhang H. (2000). "Shareholding Structure and Corporate Performance of Partially Privatized Firms: Evidence From Listed Chinese Companies", Pacific-Basin Financial journal, 8(5):587-610. 
Doğan, M. ve Topal, Y. (2015). "Sahiplik Yapısının Firma Performansı Üzerine Etkisi: Türkiye Örneği” Süleyman Demirel Üniversitesi İktisadi ve İdari Bilimler Fakültesi Dergisi, 20(4):165-177

Dwivedi, N. ve Jian, A. K. (2002). "Corporate Governance and PErformance of Indian Firms: The Effect of Board Size and Ownership", Employee Responsibilities and Rights Journal, 17(3):161-172.

Estrin, S. ve Rosevear, A. (1999). "Enterprise Performance and Corporate Governance in Ukraine", Journal of Comparative Economics, 27(3):442-458.

Fazlzadeh, A., Hend1, A. T. ve Mahboubi, K. (2011). "The Examination of the Effect of Ownership Structure on Firm Performance in Listed Firms of Tehran Stock Exchange", International Journal of Business and Management, 6(3):249-266.

Gençtürk, M. ve Usul, H. (2003). "Finansal Krizlerin Hisse Yoğunluğu Açısından Şirket Performansına Etkileri ve Bankacılık Sektöründe Bir İnceleme", G.Ü. İIBF. Dergisi, $3: 125-132$.

Gonenç, H. (2006). "Ownership Concentration and Corporate Governance: A Simultaneous Equation Framework For Turkish Companies", İnternet Adresi: http://papers.ssrn.com/sol3/papers.cfm?abstract_id=498263, Erişim Tarihi: 10.12.2013.

Greene, W., H. (2003). Econometric Analysis, Fifth Edition, New York: Prentice-Hall International, Inc.,

Gündüz, L. ve Tatoğlu E. (2003). "A Comparison of the Financial Characteristics of Group Affiliated and Independent Firms in Turkey", European Business Review, 15(1):48-54.

Gürbüz, A. O. ve Yakup, E. (2004). Kurumsal Yönetim: Türkiye'deki Durumu ve Geliştirilmesine Yönelik Öneriler, 1. Baskı, İstanbul: Literatür Yayınc1lık.

Gürsoy, G. ve Aydoğan, K. (1999). "Equity Ownership Structure, Risk Taking and Performance: An Empirical Investigation in Turkish Companies", ERC/METU International Conference in Economics, Ankara, Turkey.

Hiraki, T., Inoue H. Ito A. Kuroki F. ve Asuda H. (2003). "Corporate Governance and Firm Value in Japan: Evidence From 1985 to 1998", Pasific-Basin Finance Journal, 11(3):239-265.

Hu, Y. ve Izumida, S. (2008), "The Relationship Between Ownership and Performance: A Review of Theory and Evidence", International Business Research, 1(4):72-81.

Iş1k, O. ve Soykan, M. E. (2013). "Large Shareholders and Firm Performance: Evidence From Turkey" European Scientific Journal, 9(25):23-37.

Jensen, M. C. ve Mecking, W. H. (1976). "Theory of the Firm: Managerial Behavior, Agency Costs and Ownership Structure" http://papers.ssrn.com/abstract=94043.

Kapopoulos, P. ve Lazaretou, S. (2007). "Corporate Ownership Structure and Firm Performance: Evidence from Greek Firms", Corporate Governance: An International Review, 15(2):144-158.

Karoğlu, E. (2016). "Vekalet Kuramı Perspektifinden Yönetim Kurulu Kompozisyonunun Finansal Performans Üzerindeki Etkisi: BIST İmalat Sektörü Örneği” Balkan ve Yakın Doğu Sosyal Bilimler Dergisi, 2(1):65-77.

Kılıç, M. (2014). "Yönetim Kurulu Yapısının İşletme Performansına Etkisi: Türkiye'de Bir Uygulama", Muhasebe Bilim Dünyası Dergisi, 16(3):33-56.

Konak, F. ve Kendirli, S. (2013). "Sermaye Yoğunlaşmasının Firma Performansı Üzerine Etkisi: BIST Gıda ve İçecek Endeksi Uygulaması", Uluslararası İktisadi ve İdari İncelemeler Dergisi, 8(15):123-133.

Kula, V. (2006). Kurumsal Yönetim Hissedarların Korunması Uygulamaları ve Türkiye Örneği, İstanbul: Papatya Yayıncılık. 
Lappalainen, J. ve Niskanen, M. (2012). "Financial Performance of SMEs: Impact of Ownership Structure and Board Composition", Management Research Review, 35(11): 1088-1108.

Le, N. N. D. ve Thi, N. N. D., (2016). "An Examination of the Relationship of Corporate Governance to Firm Performance: Empirical Evidence From Vietnamese Listed Companies", International Journal Of Financial Research, 7(4):190-197.

Lemmon, M. L. ve L,ns, K. V. (2003). "Ownership Structure, Corporate Governance and Firma Value: Evidence From The Esat Asian Financial Crisis", The Journal of Finance, LVIII(4):1445-1468.

Mandac1, P.E. ve Gümüş, G.K. (2010). "Ownership Concentration Managerial Ownership and Firm Performance: Evidence From Turkey", South East European Journal of Economics and Business, 5(1):57-67.

Mitton, T. (2002). "A Cross-Firm Analysis of the Impact of Corporate Governance on the East Asian Financial Crisis", Journal of Financial Economics, 64:215-241.

Morck, R., Shleifer, A. ve Vishny, R. W. (1988). "Management Ownership and Market Valuation: An Empirical Analysis", Journal of Financial Economics, 20:293-315.

Mcconnell, J. J. ve Servaes, H. (1990), "Additional Evidence on Ewuity Ownership and Corporate Value", Journal of Financial Economics, 27:595-612.

Okan, T., Sarı, S. ve İlhan N. T. (2014). "Yönetim Kurulu Yapısı ile Finansal Performans Arasındaki İlişkide Uluslararası Çeşitlenmenin Aracılık Etkisi", İstanbul Üniversitesi İşletme Fakültesi İşletme İktisadı Enstitüsü Yönetim Dergisi”, 25(77):39-78.

Önem, H. B. ve Demir, Y. (2015). "Mülkiyet Yapısının Firma Performansına Etkisi: BIST İmalat Sektörü Üzerine Bir Uygulama", Süleyman Demirel Üniversitesi Vizyoner Dergisi, 6(13):31-43

Riewsathirathorn, P., Jumroenvong, S. ve Jiraporn, P. (2011). "The Impact of Ownership Concentration on Bank Performance and Risk-taking: Evidence from East Asia, Working Paper. Thammasat University, Bangkok, Thailand.

Rouf, A. (2012). "The Relationship Between Corporate Governance and Value of The Firm in Develeopment Countries: Evidence From Bangladesh" Journal of Economics and Business Research, XVIII(1):73-85.

Stock, J.H. ve Watson, M.W. (2011). Ekonometriye Giriş, (Çev: Bedriye Saraçoğlu), 1. Bask1, Ankara: Efil Yayınevi.

Şamiloğlu, F. ve Ünlü, U. (2010). "Sahiplik Yapısı ve Firma Performansı Arasındaki İlişki: İMKB 100 Endeksi Firmaları Üzerine Bir Uygulama", Muhasebe ve Finansman Dergisi (MUFAD), 46:66-73.

Tatoğlu, Yerdelen, F. (2012). Panel Veri Ekonometrisi, 1. Bask1, İstanbul: Beta Yayınc1lık.

Tanrıöver, C. ve Aksoy, E. E. (2010). "IMMKB'de İşlem Gören Şirketlerde Ortaklık Yoğunlaşmasının Firma Performansı Üzerine Etkileri”, Muhasebe ve Finansman Dergisi, 46:216-231.

Thomsen, S. ve Pedersen, T. (2000). "Ownership Structure and Economic Performance in the Largest European Companies", Strategic Management Journal, 21:689-705.

Tükenmez, N. M., Gençtürk, A. G ve Kabakcı, C. Ç. (2016). "Türk Bankacılık Sektöründe Sahiplik Yoğunlaşması ile Finansal Performans İlişkisinin İncelenmesine Yönelik Ampirik Bir Çalışma", Atatürk Üniversitesi İktisadi ve İdari Bilimler Dergisi, 30(3):625-644.

Ülgen, H. ve Mirze, S. K. (2013). Isşletmelerde Stratejik Yönetim, 6. Bask1, İstanbul: Literatür Yayıncilik. 
Ünlü, U., Bayrakdaroğlu, A. ve Şamiloğlu, F. (2011). "Yönetici Sahipliği ve Firma Değeri: İMKB için Ampirik Bir Uygulama", Ankara Üniversitesi SBF Dergisi, 66(2): 201-214.

Wooldridge, J.M. (2002). Econometric Analysis of Cross Section and Panel Data, The MIT Press Cambridge, London, England.

Xu, X. ve Wang, Y. (1999). "Ownership Structure, Corporate Governance and Firm Performance: The Case of Chinese Stock Companies", World Bank Policy Research Working Paper ; $1-54$.

Yıldırım, M. (2007). Türkiye'de Kurumsal Yönetim ve Şirketlerin Finansal Performansları Üzerine Etkileri, Doktora Tezi, Dokuz Eylül Üniversitesi, Sosyal Bilimler Enstitüsü, İzmir.

Y1lgör, A. G. ve Yücel, E. (2012). "İşletmelerin Sahiplik Yapısının İncelenmesi: Sahiplik ve Kontrol Ayrımı Konusunda Çıkarımlar”, Uluslararası Yönetim ve İktisat ve İşletme Dergisi, 8(16):41-58.

Yurtoğlu, B. B. (2000). "Ownership, Control and Performance of Turkish Listed Firms", Empirical, 27:193-22. 